\title{
A framework for the alignment of ICT with Green IT
}

\author{
Manuel Landum ${ }^{1, *}$, Maria Margarida Madeira e Moura ${ }^{1}$, Leonilde Reis ${ }^{2}$ \\ ${ }^{1}$ Universidade do Algarve, DEEI/FCT, Campus de Gambelas, Faro, Faro, 8005-139, Portugal \\ ${ }^{2}$ Polytechnic Institute of Setúbal, Campus do IPS, Estefanilha, Setúbal, Setúbal. 2910-761, Portugal
}

\section{A R T I C L E I N F O}

\section{Article history:}

Received: 12 December, 2020

Accepted: 28 February, 2021

Online: 20 March, 2021

Keywords:
Green IT
Environment
Information and Communication
Technologies

Keywords:

Green IT

Information and Communication

Technologies

\begin{abstract}
A B S T R A C T
The Public Administration is forced to transform itself by taking advantage of the contribution of ICT to in the process of reducing bureaucracy and increase transparency, promoting the dematerialization of processes, increasing the quality of online services, allowing greater ubiquity of access, reducing response times, in the search for improvement of the quality of life of its citizens. Decision-making should consider objectives not only technical but also financial, environmental, and social objectives, ideally aligning with Green IT. The objective of the paper is to present a framework, supported by international standards and frameworks, that allows measuring and guiding the alignment of ICT with Green IT for the optimization of practices instituted in organizations, namely in Local Government. This framework includes a qualitative component with several phases and quantitative component with a metric that allows the evaluation of alternative strategies for a given goal. The phases considered are Problem Identification; Problem assessment; Study and planning; Project; Telecommunications and Printing; Information Security; Innovation; Improvement of Citizen Service; Evaluation / opinion. The complete metric includes four valences: IT, financial, environmental, and social. The IT valence, its indicators and corresponding weights are illustrated in a practical example. The proposed framework is an innovative contribution to the area, clearly integrating the support of the perspective of Green IT and thus actively contributing to the implementation of sustainability policies and alignment with Green IT best practices in Local Government, as well as presenting with greater level of detail the components of the structure that emphasize Green IT concerns. The main expected results of the application of the framework are contributing to the implementation, in local government, of sustainable policies and good practices aligned with Green IT, whist targeting cost reduction and optimization, ubiquity of access, increased productivity and ensuring safety standards.
\end{abstract}

\section{Introduction}

This paper is an extended version of the article originally presented in 2020 at the 15 th Iberian Conference on Information Systems and Technologies (CISTI), where the themes address the alignment of public administration (PA) good practices, namely the alignment with Green IT of local administration (LA) practices [1].

The pervasive way in which Information and Communication Technologies (ICT) are currently part of our daily lives, associated with environmental concerns, motivated this work of integrating environmental sustainability aspects into information technology "Corresponding Author: Manuel Landum, Email: A55265@ualg.pt
(IT) governance. Environmental sustainability should be translated to strategic thinking within organizations and is based on three objectives, pollution prevention, product management and the use of clean technologies; these objectives incorporate underlying concerns such as carbon footprint, global warming, fossil fuels, volume of material recycling and economic sustainability [2]. The three objectives can be applied at three different levels: individual, organizational, and social. Its combination can be used to identify IS or IT deployment opportunities to improve sustainability [3].

The objective of this communication is reporting a framework that includes ICT best practices in technology governance, aligned with Green IT, where the focus is on the phases that are more 
aligned. The design of this framework was supported by international standards and frameworks, and aims at optimizing governance in organizations, namely in LA. The framework incorporates PA specific constraints into implementing best practices and how these best practices can be defined. The main contributions of this framework are based on the metrics presented, sustainability and the improvement of the ICT ecosystem.

This article is organized into four sections: firstly, in this introduction, the contextualization of the problem and the objective of the article are presented; in the second section, the literature review is presented, which includes the theoretical foundations of the supporting thematic; following, in section three, the framework that includes ICT best practices, aligned with Green IT and supported by international standards and frameworks in order to optimize practices instituted in organizations, mainly in the LA under study, is presented; finally, in the fourth section, some conclusions highlighting the consequences from the use of the framework and its contributions to the community are presented.

\section{Literature review}

The literature review, based on the collection of articles on the subject, was supported by references and citations of papers, together with keywords directed to the theme, as well as in the analysis of sustainability and the pursuit of good practices in alignment with Green IT.

\subsection{Digital Transformation}

The process of digital transformation arises in the daily life of organizations, particularly in PA and more specifically in LA, driven by the need felt to modernize internally, externalizing more and better services for their customers, in a ubiquitous way, allowing for greater mobility and freedom in the way these customers relate to the organization. And ubiquity is a good practice, aligned with Green IT.

It should be noted that "computer technology and the increasing availability of digital data are radically changing forms of research and production of knowledge" [4] in our areas. Customers seek solutions that lead to a streamlining of processes, where requests and deliveries of services are made remotely, so that they can avoid face-to-face calls, that would otherwise cause loss of time and costs. With this demand, customers press services to ensure that processes suffer digital transformation, conducing to prompt, fast and click-away responses.

The process of "digital transformation is not just about computerizing a productive system. It involves exploring these systems to develop, maintain or improve skills that a company needs or dominates. Having this idea in mind is important when a company thinks about taking the step towards digital transformation" [5]. From this, it can be inferred that digital transformation is not just about digitization of processes, and it is much more than that. From the perspective of [4], digital copies of printed theories do not transform these theories into digital theories, just as literature is much more than a mere transliteration of oral discourse.

Moreover [6], the digital transformation of society does not follow directly from digital technology. The latter is a necessary condition, but not enough. For digital transformation to take root, digital technologies must be imbued with social significance. Digital transformation implies process reengineering, creation, and optimization of flows, incorporating the acquisition of new skills and business practices. Organizations are thus driven to adhere to digital transformation and automation, maintaining or strengthening their competitive position, further enhancing the human-machine relationship, and increasing the degree of automation of processes.

\subsection{Virtualization}

Virtualization will be a way to implement the digital transformation process more quickly, being an important technique for the increasingly digital world of our daily life. One of the achievements of this technique is the creation of several servers or virtual desktops, from one or more physical machines; this allows, among other factors, to reduce the number of physical machines, leading to the reduction simultaneously of the amount of power supplies, the reduction of the time until readiness by facilitating the management of virtual machines, the reduction of energy consumption and environmental improvement and consequently leads to a decrease in the need to purchase new equipment. Virtualized data centers are designed to provide better management flexibility, lower cost, scalability, better resource utilization and energy efficiency, and thus, consequently, reducing costs with installation, maintenance, cooling, and physical space, thus contributing for an alignment with Green IT [7].

Cloud computing, or cloud computing, turns out to be one of the factors responsible for boosting virtualization, given the fact that it is defined as a shared set of virtualized resources, where in fact users access cloud resources using a unit, independent, called Virtual Machine (VM) [8]. These VMs are housed on physical servers, within large infrastructures, of data centers. Commercial offers facilitate the access to these virtualized pools of resources, providing users with nearly infinite computing resources in the form of processing power, memory, and disk space. Thus, and according to [9], the concept of virtualization is applied in cloud computing systems to help both users and owners get better use and efficient management of the cloud at the lowest cost.

Generically, virtualization is a technique that allows the reduction of resource use and contributes to environmental improvement, fostering the alignment with Green IT.

\subsection{Green IT}

Based on the alignment mentioned above, a definition was sought and a set of good practices that demonstrate it. If there is no single definition of what Green IT is, it is then considered a set of good practices about the use of computers and IT resources, in a sustainable, more efficient, and responsible way with the environment.

Green IT, as a concept, surfaces as a worldwide movement from the concern of organizations and/or individuals in preserving the environment, seeking the promotion of social and environmental responsibility, in this technological world. This movement focuses its ideals on "preserving the environment, in the search for the reduction of environmental impacts, based on sustainable practices and, in this particular case, interconnected 
with ICT" [10]. Currently, the theme is of particular interest given the problems of climate change and sustainability, considering the daily reality, where these issues need to be included in the decision-making process to contribute in a timely manner to the environmental non-aggravation.

It should be seen that as the population increases, developing or underdeveloped economies end up committing to the rapid growth of infrastructure, leading to a great pressure from the consumption of natural resources. The realization that natural resources are not inexhaustible and that it is not possible to continue with economic growth without considering the variable environment and society, opens the way to the search for new alternative solutions for the productive system, such as the concept of Sustainable Development, which aims to maintain the balance between economic growth, social equity, and the natural environment [11].

Currently, with growing concern about the impacts of environmental strategies at local and global level, there is a need to achieve development in a more environmentally responsible manner, by balancing the choices between the environmental, economic, and social aspects of sustainability [12]. It is therefore necessary for organizations, particularly those responsible for hardware development, to look at the concept of Green IT and develop policies of social and environmental responsibility. Some organizations, in response to customer pressure, already exhibit an awareness and an effort to reduce operational and technological costs, through energy efficiency, in alignment with the good practices of Green IT.

The concerns regarding ICT consider the negative impact on the environment, not only by the electricity consumed, but also by the materials used in the manufacture of hardware, such as lead, arsenic, antimony trioxide, selenium, cadmium, chromium, cobalt, and mercury. This problem of society, in particular ICT, "includes electronic waste, municipal waste, the toxicity and hazard stemming from this equipment and whose solution is to comply with the directives on electronic waste, not allowing it to be deposited in bins, but rather collected by suppliers, treated and recycled, where even some restrictions are placed on manufacturing materials and legislation to control the transfer of electronic waste between borders" [10].

It is generally accepted that in organizations the use of some resources in some processes is conducive to waste, such as energy waste, paper waste, or of other materials, time, and financial resources. In view of this fact, Green IT practices can generate financial returns, sustainability, and environmental improvement. It is necessary to raise awareness among organizations and the PA, to consider the environment, but effectively, not only with good intentions. In [13], the author defends that the perspectives of sustainability transitions emphasize the need of the public sector to adapt policies towards technological innovation, and to be institutionally redesigned. Ecological concerns that allow environmental sustainability, such as reducing the carbon footprint or reducing the use of fossil fuels, are effective if actions involving e-waste management and waste management are considered, adopting an ecological stance in the life cycle of products that allows the reduction of the quantities of equipment and materials to be recycled and the costs inherent. In this way, Haley considers the urgent need to make the transition to a low-carbon economy and has reintroduced the importance of technology-specific policy approaches [13].

In view of this scenario, more efficient resource use practices should also be considered and allow for the reduction of energy consumption, which leads to a reduction in $\mathrm{CO} 2$ emissions and reduction of energy costs in the case of virtualization. Actions that lead to paper reduction, such as dematerialization and digital transformation, are also important.

It should be noted that the implementation of sustainability policies and practices in public administration has been adopted at different paces, depending on the country, the level of administration (e.g., local versus national or central) or the activities and objectives of each organization [14]. All this depends on the organizations being willing to adopt a posture of social and environmental responsibility. The adoption of environmental practices and tools in general management is a growing reality in local public organizations as these institutions are shifting their management to sustainability, although local governments move faster than other levels of the public sector in terms of integrating environmental and sustainability aspects into operations and strategies [15]. It should also be considered that in the 2030 Sustainable Development Goals Agenda, in addition to the limited obligations of governments, there is an emphasis on impact, and the means for implementing the targets should be significantly updated [16]. Therefore, "local governments are faced with the need to be part of the change from the perspective of sustainability and integrate good practices to improve their own performance" [15].

Faced with this reality and considering the need for organizations, particularly in LA, to find sustainable ICT good practice models that require less of the environment, aligning them with Green IT, a framework is presented.

\section{The framework}

This framework for the alignment of ICT with Green IT encompasses two complementary approaches: a qualitative methodology, supported by international standards and frameworks, to provide the optimization of practices in organizations, namely in LA; a quantitative methodology for the assessment of strategies. Given the approach developed, and which can be implemented in other municipalities of the country, it is considered that the results can constitute an added value. Generally, considering the set of skills of the organization, the Chief Information Officer (CIO) should validate the suitability and the weighting factors used in the assessment of alternative strategies.

In Sections 3.1 and 3.2 an overview of the qualitative and quantitative components of the framework are presented and, where appropriate, illustrated with small instances from the use in a real case scenario.

\subsection{Qualitative components of the framework}

This component includes practices, deemed good, which are added value because they contribute simultaneously to increased productivity, increased information security, and management optimization. Different contributions towards the definition of 
these good practices were taken into consideration. Considered relevant were all those practices that contribute to economic and environmental sustainability, process optimization through dematerialization and digital transformation, combat waste, reduce materials to be recycled, reduce costs, reduce $\mathrm{CO} 2$ emissions, fostering greater alignment with Green IT. These good practices were formalized into the model. This component also incorporates sustainability factors, aligning with Green IT and includes the generality of the objectives and constraints, identified in the municipality under study, at the level of ICT.

Figure 1 represents the phases of the model, starting in phase zero, with the Identification of the Problem, followed by eight more phases, in a governance model that allows identifying good practices that align with the objective of the activity.

- Phase 0, Problem Identification.

- Phase 1, Evaluation and Continuous Improvement.

- Phase 2, Study and Planning.

- Phase 3, Project.

- Phase 4, Telecommunications and Printing.

- Phase 5, Information Security.

- Phase 6, Innovation.

- Phase 7, Improvement of Citizen Services.

- Phase 8, Evaluation/Opinion.

The model will be iterative from phase 2 to phase 6 , going through all phases up to phase 8 , where, based on the collected elements, evaluation and opinion, there may be a need to go through the entire cycle again, optimizing processes, alluding to the Plan, Do, Check and Act (PDCA) cycle, but this with more phases. It should be noted that when applying the model, choices are made and, in the corresponding qualitative component, greater weights are given to greater sustainability.

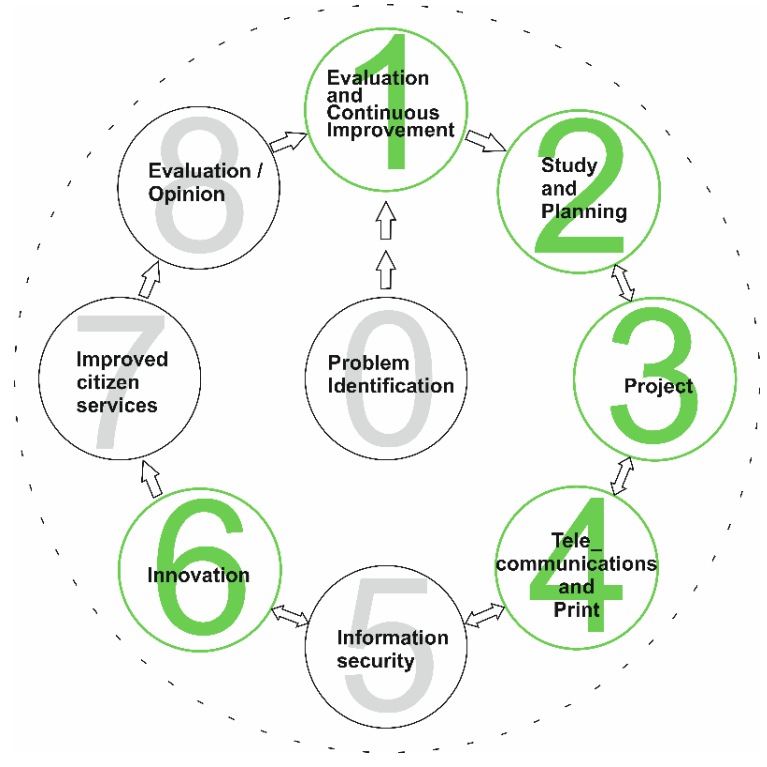

Figure 1 - The Framework
Complementing the context of the main objective of this article, it is intended to deepen the phases where the alignment of good practices with Green IT; consequently, the phases 1, 2, 3, 4 and 6, marked in green color, are more focused.

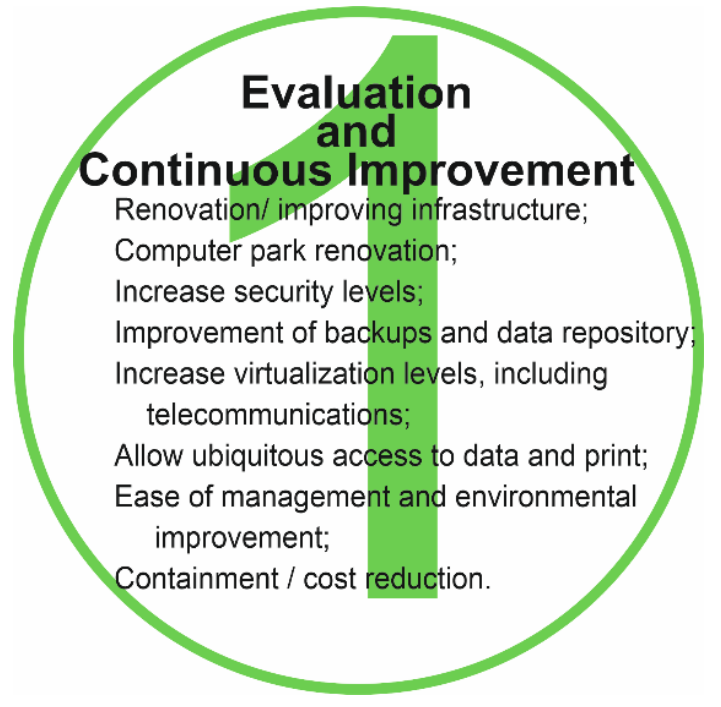

Figure 2 - Phase 1, Evaluation and Continuous Improvement

In Phase 1, as illustrated in Figure 2, the goal is to study the possibility of moving from a traditional model to a virtualized infrastructure model, including telecommunications. This virtualized model can be a way to reduce costs with maintenance contracts, enhance increased information security and internal know-how in the maintenance and configuration tasks of the virtual plant. In the context of this evaluation phase, it is also intended to ensure the ubiquity of access, between the various buildings, decentralized throughout the county, providing the data on impressions to ensure greater mobility of people and autonomy daily [17]. Particularly relevant are the two final tasks in this Phase 1: the evaluation of ease of management and environmental improvement, always present throughout this project the environmental preservation and the use of technologies that allow this preservation, in alignment with Green IT; and the containment equation or whenever possible, cost reduction without compromising the project [17].

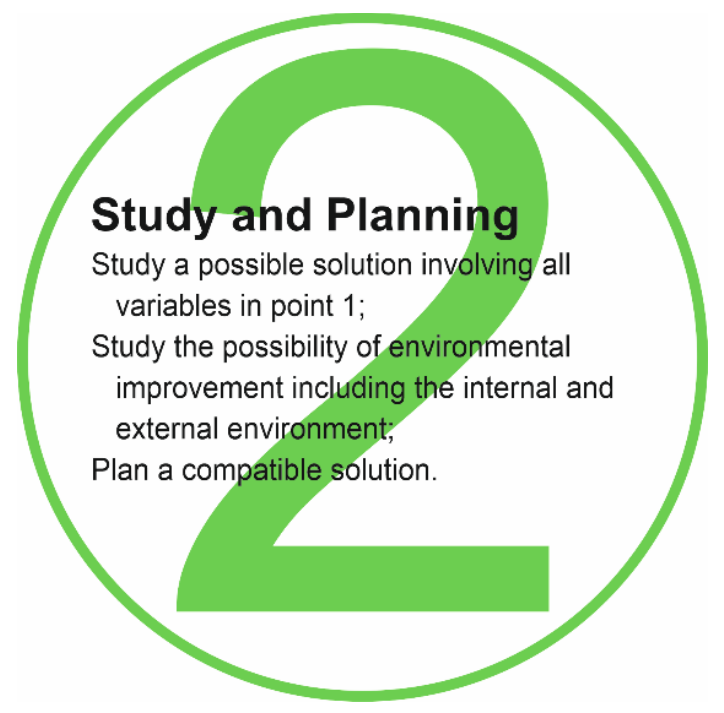

Figure 3 - Phase 2, Study and Planning 
Phase 2, as summarized in Figure 3, begins with the Study and Planning, having been concluded the assessment of the constraints encountered, the needs for improvement, and upgrade of the solution.

This phase should be considered as one of the most relevant and decisive in the conduct of the whole approach, although we are facing an iterating process between this phase and phase 6 , as it will be based on the results of the study and planning carried out, that all subsequent phases will be supported, and where the need to change the areas outlined may bring unexpected costs to the organization or unforeseen results [17]. Thus, it is intended to study an approach that allows the involvement of all variables described in the previous phase, and that simultaneously includes the possibility of environmental improvement, encompassing both the internal environment and the external environment., aligning with Green IT. Consequently, there is the intention of planning a solution that can be compatible and retro compatible with the existing one, used, at the level of ICT, both hardware and software, also minimizing the costs of the final solution.

After the completion of the Study and Planning, Phase 3 begins (see Figure 4) where the architecture will be developed in design.

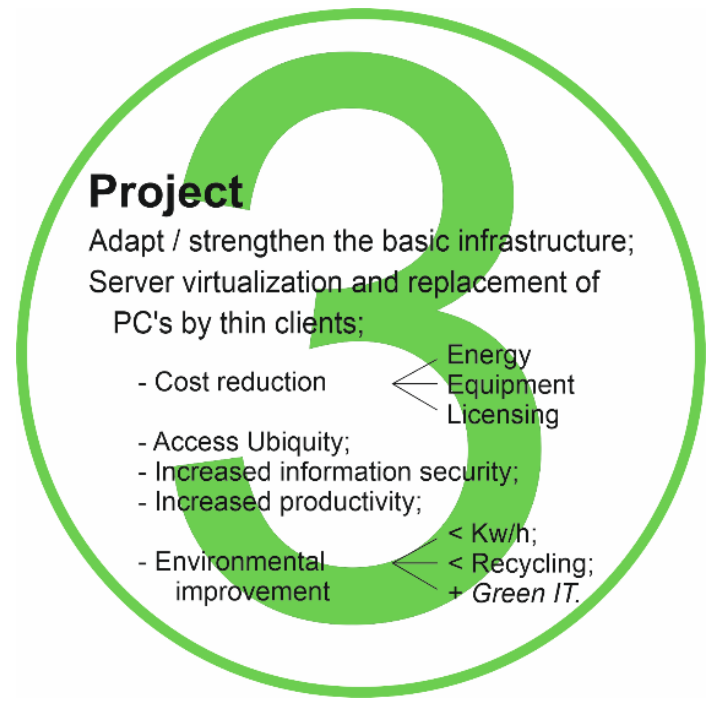

Figure 4 - Phase 3, Project

The input of this phase will be based on the output of the previous phases, where it is intended to adapt and strengthen the basic infrastructure as fundamental support of the project.

The aim is to build a data center internal to the municipality, which can serve to housing the active and passive equipment necessary for the interconnection of all buildings of the municipality, through routing and switching, internet connection and data storage, to allow ubiquity of access to data and printing, increasing productivity increase and without compromising information security, preferably aligned with Green IT. This infrastructure should be in a virtualized environment, as described in phase 1 and all equipment must be supported and connected to a UPS capable of maintaining the infrastructure for some time in the event of a power outage. In addition to server virtualization, with the creation of several VMs, in a distributed environment, the replacement of most PC's, in the end of life, by thin clients that will connect to the servers, that after the cost/benefit assessment and considering the requirements, one can opt for connections by Remote Desktop Protocol (RDP), or connections to Virtual Desktop Infrastructure (VDI). Costs must be evaluated together with the benefits of the adopted solution [17]. Also, in the field of virtualization, it is noted that the replacement of end-of-life PC's by thin clients is conducting to reduction of costs, particularly energy as will be proven later, not undermining the alignment with Green IT.

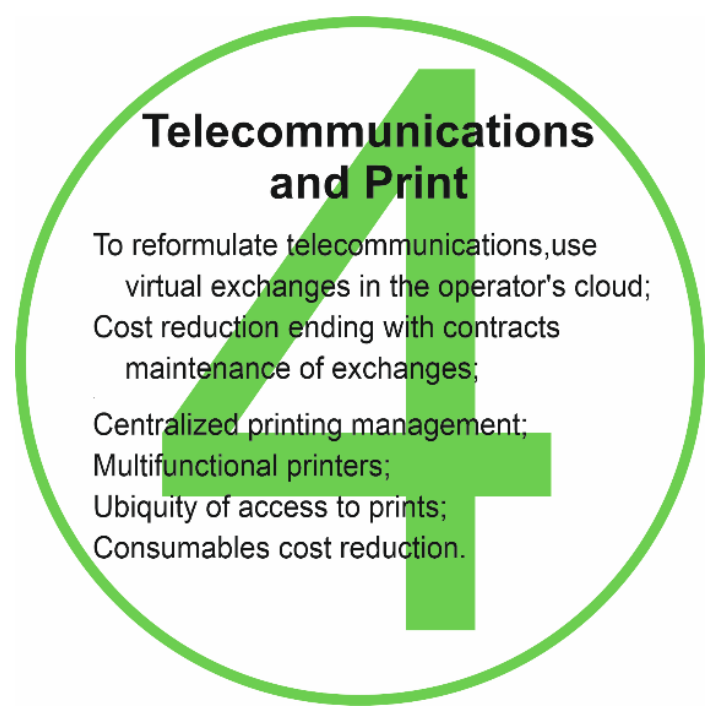

Figure 5 - Phase 4, Telecommunications and Print

In phase 4 , one targets the solutions that allow the reformulation of telecommunications and printing, as can be seen in Figure 5 to optimize these two areas of resource expenditure and equate how contributions to environmental improvement and containment or cost reduction can be achieved. Although distinct, it is considered that they should be treated in an integrated way per se, because they group a set of features and valences related to digital transformation and that allow, in this context, the clear expression of added value for the organization.

Specifically, in telecommunications, it was identified a critical situation with the continued use of physical telephone centers in old, deteriorated buildings, where humidity prevails, implying constant breakdowns and obviously the breakdown of telecommunications between buildings and the exterior, with the consequent constraints and intrinsic costs. Another problem is the difficulty of daily management of IT technicians, hindered by the need to go to the different locations and locally deal with issues; an integrative solution should be achieved in the future and one that allows facilitated management, without increased costs [17]. Even if the option is virtual telephone centers, we will also be contributing to environmental improvement, with the reduction of the number of materials to be recycled and, after checking the numbers, one may state that a reduction in energy consumption occurred, as less movement will translate to a reduction of $\mathrm{CO} 2$ emissions to the atmosphere, which will help in reducing the ozone hole, clearly in alignment with Green IT.

Regarding printing, one of the concerns of the municipality, or of any municipality or organization, is the high costs, of the equipment and space occupied, of the printing itself, in terms of paper and ink or tonner, as well as of keeping stock of printing consumables, worsened by the proliferation of various models, 
requiring the increase of stocks, contributing all this to the increase of costs. It should be noted that there is also the stock management process: adding to the need of a large investment due to the number of different models, it may happen that cartridge stocks are renewed by the terminus of their shelf life, even if the corresponding printers have already been disposed of and information not propagated [17].

Thus, solutions should be sought to reduce the number of equipment and achieve homogeneity of models, contributing to scale savings, simultaneously aiming to reduce or end stocks, and so contributing to process optimization, faster response and containment or cost reduction. The ubiquity of access, in a safe way, to printed documents is a target allowing better productivity and improvement of processes in everyday life, to those who use it in the different buildings. As far as printing is concerned, the decision to be taken should also be aligned with environmental improvement, where the acquisition of new equipment, and therefore, the amount and type of materials to be recycled in the future, is also in alignment with Green IT is to be reduced.

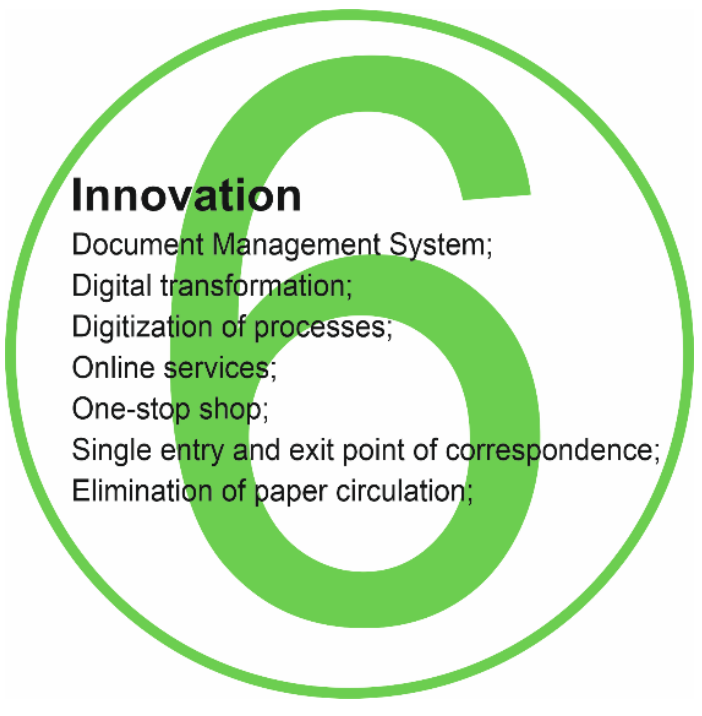

Figure 6 - Innovation

Phase 6 will address the innovative aspects that the PA, in this case and more properly LA, can and should provide its citizens, customers of its organization, with more and better services preferably innovative and strategic, at the distance of a click, thus saving travel costs and loss of time. To this effect, the LA must take the path of digital transformation, adopting the digitization of processes based on a document management system, unique and transversal to the whole organization, that allows integration with online services, providing added value services to citizens.

Referring to innovation, it was stated [18] that the word innovate is widely used when we approach transformation and strategy. This is the path that has been outlined for the municipality under study. Realistic and well-founded transformation should be seen as a future perspective and seen as digital transformation; as such it will be necessary that on the part of organizations and the $\mathrm{PA}$, there is a concerted strategy so that a new, faster, collaborative mode of action among several actors can implement responses to the needs and perspectives of citizens and citizens in general [17]. There is an increasing interest in the form of stimulating innovation in the public sector, being noted the mention [19] of recent research points of collaboration between actors as a factor of superior innovation. In this sense, the public sector or other nongovernmental organization consider in their daily agenda the incentive to innovation, by political, economic weight and quality of services. Similarly, there is some agreement [20] with the previous statement and the recognition that the economic weight of these entities leads to the growing political interest in stimulating innovation in PA, which may culminate in a marked improvement and increased efficiency in the use of resources, adding quality of public services and preparing to face the most varied social challenges.

Innovation can be another catalyst for improving services, increasing productivity, and, containing or reducing costs, aligned with Green IT good practices, can bring benefits at various levels.

\subsection{Quantitative component of the framework}

The qualitative component of the framework aims at evaluating different alternatives. It was understood that alignment with Green IT can be measured through four dimensions [21]:

IT valences: Hardware, software, information systems, security, governance.

Financial valences: Direct and/or indirect costs of IT.

Environmental valences: Environmental impact including $\mathrm{CO} 2$ emissions, use of natural resources, contribution to global warming, recycling.

Social valences: satisfaction of the citizen, speed of response, number of trips, time on the move, image of the municipality.

Thus, the Green IT alignment (1) metric includes the IT, financial (Fin), environmental (Env), and social (Soc) dimensions.

Green IT alignment $=0.3 \mathrm{IT}+0.2 \mathrm{Fin}+0.3 \mathrm{Env}+0.2 \mathrm{Soc}(1)$

In each dimension, the evaluation is achieved by a set of weighted indicators. The indicators correspond to the valences identified. The direction - positive (+) or negative (-) value - of the indicators will convey if it furthers or hinders the green alignment, respectively. The relative relevance of an indicator is conveyed by a weight (in \%).

Greater sustainability, in one case, may be obtained by the virtualization of the infrastructure in the data center of the municipality, which will favor the exchange of end-of-life computers by thin clients. As an example of this component of the framework we will consider two strategies: maintain PCs or replace them by thin clients. It must be noted that some indicators are not applicable to the current case study and are presented but not included in the comparison; a one-year timeframe was considered; costs and prices refer to the time of writing; to illustrate the application, we will instantiate the financial dimension.

Table 1 lists some of the IT indicators that shape operational objectives, especially those aimed at optimizing reliability, service availability, management times, productivity, breakdown reduction, access ubiquity and information security; in short, the relevant IT indicators when in the search for sustainability. 
Table 1: IT indicators

\begin{tabular}{|l|c|r|}
\hline Indicators & Direction & $\begin{array}{c}\text { Weight } \\
\text { factor }\end{array}$ \\
\hline reliability & + & $20 \%$ \\
\hline management times & - & $5 \%$ \\
\hline service availability & + & $10 \%$ \\
\hline productivity & + & $15 \%$ \\
\hline quality management & + & $5 \%$ \\
\hline number of malfunctions & + & $10 \%$ \\
\hline information security & + & $20 \%$ \\
\hline ubiquity of access & + & $10 \%$ \\
\hline $\begin{array}{l}\text { reduction of file space on digital } \\
\text { support }\end{array}$ & & $5 \%$ \\
\hline
\end{tabular}

The PA should pay particular attention to its cost management, as on the one hand it strives to remain competitive about the technology at its disposal, on the other hand it should be moderate and contain the costs to keep the budget balanced. Nowadays the IT sector is a strategic asset within each organization and digital transformation assumes significant role in an organization although the study and adoption of technological solutions may raise costs in the annual budget, informed choices reflect good strategic planning preferably aligning with Green IT.

Table 2 illustrates the measurement of some financial indicators demonstrating infrastructure and energy costs, energy consumption and equipment lifetime in the municipality.

Table 2: Financial indicators and instantiated values

\begin{tabular}{|l|c|c|c|c|}
\hline Indicators & Direction & PC & $\begin{array}{c}\text { Thin } \\
\text { client }\end{array}$ & $\begin{array}{c}\text { Weight } \\
\text { factor }\end{array}$ \\
\hline $\begin{array}{l}\text { cost of } \\
\text { infrastructure }\end{array}$ & - & $€ 650$ & $€ 250$ & $45 \%$ \\
\hline $\begin{array}{l}\text { equipment } \\
\text { lifetime }\end{array}$ & + & 4 Years & 7 Years & $25 \%$ \\
\hline $\begin{array}{l}\text { energy } \\
\text { consumption }\end{array}$ & - & $377 \mathrm{Wh}$ & $5 \mathrm{Wh}$ & $30 \%$ \\
\hline
\end{tabular}

After normalizing the financial indicators, one would reach the values $-0,61$ and $+0,08$, for $\mathrm{PC}$ and thin client, respectively, indicating that the latter will better approach Green IT.

Society today is already governed by the maximum environmental improvement or preservation of nature, as such, organizations should also be aware that it needs to be properly aligned with the business, but not to be able to improve a good alignment of IT with Green IT, as it will certainly become more expensive to remedy than to prevent environmental problems.

Table 3 presents some environmental indicators which involve $\mathrm{CO} 2$ emissions, care for nature preservation, sustainability and recycling, and concerns about global warming. These indicators also demonstrate the existing concern with environmental quality, also aligned with the financial indicators contained in Table 2.
Table 3: Environmental indicators

\begin{tabular}{|l|c|c|}
\hline Indicators & Direction & $\begin{array}{l}\text { Weight } \\
\text { factor }\end{array}$ \\
\hline CO2 emissions & - & $50 \%$ \\
\hline preservation of natural resources & + & $20 \%$ \\
\hline suitability for recycling & + & $10 \%$ \\
\hline global warming & - & $20 \%$ \\
\hline
\end{tabular}

Achieving excellence in the valences of IT, Financial and Environmental, implies, achieving the satisfaction of citizens, improving the image of the municipality, the well-being of employees, increasing the speed of response to processes, avoiding travel to the service services, which contributes to the reduction of costs to the citizens themselves, therefore, a social improvement that should not be bleached. Reducing calls to care also contributes to reducing $\mathrm{CO} 2$ emissions, once again in alignment with Green IT and environmental improvement.

The mirrored indicators in Table 4 corroborate the opinion already demonstrated by the authors and are proof of the above, and should be taken into account, as an example of social responsibility in PA, which can also be understood as environmental social responsibility, in a clear allusion to the respect shown by people and human values and simultaneously by environmental causes [21].

Table 4: Social indicators

\begin{tabular}{|l|c|c|}
\hline Indicators & Direction & $\begin{array}{l}\text { Weight } \\
\text { factor }\end{array}$ \\
\hline satisfaction of the citizen & + & $10 \%$ \\
\hline image of the municipality & + & $10 \%$ \\
\hline well-being of employees & - & $10 \%$ \\
\hline time in the circulation of information & - & $15 \%$ \\
\hline speed in the response to the citizen & + & $10 \%$ \\
\hline number of trips to the service & - & $10 \%$ \\
\hline loss of time on travel & - & $10 \%$ \\
\hline travel costs to citizens & - & $15 \%$ \\
\hline service times & - & $10 \%$ \\
\hline
\end{tabular}

Finally, the evaluation of a new process or the global activity be qualitatively resumed as presented in Table 5 .

Table 5: Green IT Alignment

\begin{tabular}{|c|l|}
\hline Nominal score & Qualitative score \\
\hline$<=20 \%$ & Very little aligned \\
\hline$>20 \% \wedge<=45 \%$ & Little lined up \\
\hline$>45 \%^{\wedge}<=75 \%$ & Aligned \\
\hline$>75 \%^{\wedge}<=90 \%$ & Very aligned \\
\hline$>90 \% \wedge 100 \%$ & Strongly aligned \\
\hline
\end{tabular}


This model can be used to support strategic decisions and informed choice on changes such as substituting desktop computers by thin clients or making services available online can be facilitated.

\section{PC vs Thin Client in detail}

The reasoning between the implementation of PCs or Thin Clients regarding consumption, costs, and quantity of materials to be recycled, is shown in Table 6 . The implementation of thin clients allows the reduction of energy consumption, contributing to the reduction of the carbon footprint and environmental improvement. As they are small equipment, they also allow the reduction of the number of materials to be recycled. They simultaneously allow the reduction of management times, which means increased productivity, and licensing costs are also lower, not in any way decorating the quality of service and information security.

Table 6: Comparison PC - Thin Client

\begin{tabular}{|l|c|c|}
\cline { 2 - 3 } \multicolumn{1}{c|}{} & PC & Thin Client \\
\hline Power supply & $600 \mathrm{~W}$ & $30 \mathrm{~W}$ \\
\hline Average consumption & $377 \mathrm{Wh}$ & $5 \mathrm{Wh}$ \\
\hline Weight & $7,900 \mathrm{~kg}$ & $0,240 \mathrm{~kg}$ \\
\hline
\end{tabular}

In the calculation of annual consumption, it was considered that the equipment of individual use is connected 7 hours a day, 5 days a week for 48 weeks. Whereas a PC consumes $377 \mathrm{Wh}$ [22], if connected 7 hours a day you will have an annual consumption of about $633.40 \mathrm{kWh}$. Likewise, considering that a thin client consumes $5 \mathrm{Wh}$ [23], if you are connected the same 7 hours a day, you will have an annual consumption of about $8.40 \mathrm{kWh}$. Comparing the values of the two equipment, there is a reduction in energy consumption in the order of $625 \mathrm{kWh}$ year. If we use 400 thin clients then we will have a reduction in annual energy consumption of $262 \mathrm{MWh}$, which at an average cost of $€ 0.165$ per $\mathrm{kWh}$, translates into a cost reduction of around $€ 41,250.00$ per year.

Regarding the number of materials to recycle, it is noted that a PC has about 7,900 kg of material and the thin client has only 0.240 $\mathrm{kg}$, and there is a gain in the reduction of materials to be recycled in the exchange of the PC for thin client. It should also be noted that the lack of treatment of these wastes, through the recycling of equipment, may lead to contamination of soil, water, and air, considering heavy metals and toxic substances, existing in computer components, such as cadmium, lead, bromine, copper, and nickel present in small quantities in equipment and devices, especially boards and that affect both people and animals and plants.

\section{Conclusions}

It has been assumed that the implementation of ICT measures, which address sustainability concerns, is crucial. Thus, it was possible to identify and quantify options to optimize established practices, thus contributing assertively to sustainability. About the Green IT, this article has several contributions, namely on the presentation of indicators for the reduction of energy consumption, contributing to the reduction of costs and the carbon footprint and consequent environmental improvement. Another aspect of Green IT focuses on reducing the volume of materials to be recycled and its pollutants, considering the replacement of computers by thin clients. In addition to the IT aspect, the financial aspect has also been exemplified, where it has been shown that the alignment of IT with Green IT can also be a boost in reducing costs, both in equipment costs, in increasing the life of the same, by reducing consumption and the number of materials for recycling, obviously aligning with Green IT.

Environmental indicators have shown that it is possible in the PA to contribute to an improvement in environmental quality, without increasing costs and technological developments, in reducing the carbon footprint. Finally, the four strands presented here, it was also possible to demonstrate that the social aspect is no less important and that it is possible in the PA, in this case in LA, to contribute to the satisfaction of citizens, by increasing the speed in response, by reducing the number of visits to services, which in itself end up contributing to the reduction of time losses and the reduction of travel costs, which eventually contribute to the improvement of environmental quality, increased confidence in THE and the improvement of the image of the municipality, still allied to the improvement of workers' working conditions, all aligned with Green IT.

The main contribution of this work is the example of a model to focus efforts to optimize ICT management practices that integrate environmental improvement and quality in a sustained manner. The main conclusions of the exercise presented here illustrate how the model increases productivity by reducing management times and containing or reducing costs in ICT. Based on the proposed framework and as a possible line of research to be developed, it is considered that the inclusion of weights in the various stages of the cycle allows their use in various real environments, such as local authorities. An aggregating instrument of all the information inherent in the framework may be another line of future research and may culminate in its development and improvement.

\section{Conflict of Interest}

The authors declare no conflict of interest.

\section{References}

[1] M. Landum, M.M.M. Moura, L. Reis, 'ICT Good Practices in alignment with Green IT', in Iberian Conference on Information Systems and Technologies, CISTI, IEEE, Sevilha, 2020, doi:10.23919/CISTI49556.2020.9141166.

[2] S.L. Hart, 'Beyond greening: strategies for a sustainable world', Harvard Business Review, 75(1), 66-77, 1997.

[3] M. Boudreau, Marie-Claude and Chen, Adela and Huber, 'Green IS Building Sustainable Business Practices', Information Systems: A Global Text, 1--7, 2008.

[4] S. Roth, H.F. Dahms, F. Welz, S. Cattacin, 'Print theories of computer societies. Introduction to the digital transformation of social theory', Technological Forecasting and Social Change, 149, 119778, 2019, doi:10.1016/j.techfore.2019.119778.

[5] L. Moreira, 'A quarta revolução industrial no setor metalomecânico português', 2019.

[6] J.S. Guy, 'Digital technology, digital culture and the metric/nonmetric distinction', Technological Forecasting and Social Change, 145, 55-61, 2019, doi:10.1016/j.techfore.2019.05.005.

[7] M.F. Bari, R. Boutaba, R. Esteves, L.Z. Granville, M. Podlesny, M.G Rabbani, Q. Zhang, M.F. Zhani, 'Data Center Network Virtualization: A Survey', IEEE Communications Surveys \& Tutorials, 15(2), 909-928, 2013, doi:10.1109/SURV.2012.090512.00043. 
[8] A. Satpathy, S.K. Addya, A.K. Turuk, B. Majhi, G. Sahoo, 'Crow search based virtual machine placement strategy in cloud data centers with live migration', Computers \& Electrical Engineering, 69, 334-350, 2018, doi:10.1016/j.compeleceng.2017.12.032.

[9] M. Noshy, A. Ibrahim, H.A. Ali, 'Optimization of live virtual machine migration in cloud computing: A survey and future directions', Journal of Network and Computer Applications, 110, 1-10, 2018, doi:10.1016/j.jnca.2018.03.002.

[10] M. Landum, Cloud na administração local: estudo de caso, Escola Superior de Ciências Empresariais, 2013.

[11] E. Coral, 'Modelo de planejamento estratégico para a sustentabilidade empresarial', Universidade Federal de Santa Catarina, 282, 2002.

[12] A. Leoneti, A. Nirazawa, S. Oliveira, 'Proposta de índice de sustentabilidade como instrumento de autoavaliação para micro e pequenas empresas (MPEs)', REGE - Revista de Gestão, 23(4), 349-361, 2016, doi:10.1016/j.rege.2016.09.003.

[13] B. Haley, 'Designing the public sector to promote sustainability transitions: Institutional principles and a case study of ARPA-E', Environmental Innovation and Societal Transitions, 25, 107-121, 2017, doi:10.1016/j.eist.2017.01.002.

[14] I. Figueira, A.R. Domingues, S. Caeiro, M. Painho, P. Antunes, R. Santos, N. Videira, R.M. Walker, D. Huisingh, T.B. Ramos, 'Sustainability policies and practices in public sector organisations: The case of the Portuguese Central Public Administration', Journal of Cleaner Production, 202, 616630, 2018, doi:10.1016/j.jclepro.2018.07.244.

[15] L. Nogueiro, T.B. Ramos, 'The integration of environmental practices and tools in the Portuguese local public administration', Journal of Cleaner Production, 76, 20-31, 2014, doi:10.1016/j.jclepro.2014.03.096.

[16] J.H. Spangenberg, 'Hot Air or Comprehensive Progress? A Critical Assessment of the SDGs', Sustainable Development, 25(4), 311-321, 2017, doi:10.1002/sd.1657.

[17] M.A. dos S. Landum, L. Reis, M.M.M. Moura, Concept of Approach to Optimize ICT Management Practices, 174-199, 2021, doi:10.4018/978-17998-4099-2.ch009.

[18] M. Camacho, 'Christian Bason: Design for Public Service', She Ji: The Journal of Design, Economics, and Innovation, 2(3), 256-268, 2016, doi:10.1016/j.sheji.2017.02.002.

[19] J. Torfing, 'Collaborative innovation in the public sector: the argument', Public Management Review, 21(1), 1-11, 2019, doi:10.1080/14719037.2018.1430248.

[20] A. Arundel, C. Bloch, B. Ferguson, 'Advancing innovation in the public sector: Aligning innovation measurement with policy goals', Research Policy, 48(3), 789-798, 2019, doi:10.1016/j.respol.2018.12.001.

[21] M. Landum, M.M.M. Moura, L. Reis, 'Evaluation of Green IT and Local Administration', ITEMA 2020 Conference Proceedings (pre-draft), Serbia, 2020.

[22] Extreme, Power Supply Calculator - PSU Calculator| OuterVision, Feb. 2021.

[23] DELL, Wyse 3040 Thin Client for Virtual Desktop Experience | Dell USA, Feb. 2021. 